\title{
Testing and Micromechanical Modelling of Rockfill Materials Considering the Effect of Stress Path
}

\author{
Wang Feng, ${ }^{1,2}$ Chi Shichun, ${ }^{1,2}$ Li Shijie, ${ }^{3}$ and Jia Yufeng ${ }^{1,2}$ \\ ${ }^{1}$ The State Key Laboratory of Coastal and Offshore Engineering, Dalian University of Technology, Dalian, Liaoning 116024, China \\ ${ }^{2}$ Institute of Earthquake Engineering, Faculty of Infrastructure Engineering, Dalian University of Technology, Dalian, \\ Liaoning 116024, China \\ ${ }^{3}$ HydroChina Kunming Engineering Corporation, Kunming 650051, China
}

Correspondence should be addressed to Jia Yufeng; jiayf130@dlut.edu.cn

Received 7 August 2016; Revised 8 October 2016; Accepted 18 October 2016

Academic Editor: John D. Clayton

Copyright (C) 2016 Wang Feng et al. This is an open access article distributed under the Creative Commons Attribution License, which permits unrestricted use, distribution, and reproduction in any medium, provided the original work is properly cited.

We have extended the micromechanics-based analytical (M-A) model to make it capable of simulating Nuozhadu rockfill material (NRFM) under different stress paths. Two types of drained triaxial tests on NRFM were conducted, namely, the stress paths of constant stress ratio (CSR) and the complex stress paths with transitional features. The model was improved by considering the interparticle parameter variation with the unloading-reloading cycles and the effect of the stress transition path. The evolution of local dilatancy at interparticle planes due to an externally applied load is also discussed. Compared with Duncan-Chang's E-u and EB models, the improved model could not only better describe the deformation properties of NRFM under the stress path loading, but also present the volumetric strain changing from dilatancy to contractancy with increasing transitional confining pressures. All simulations have demonstrated that the proposed M-A model is capable of modelling the mechanical behaviour of NRFM in the dam.

\section{Introduction}

Rockfill materials (RFMs) are widely used in the constructions of rockfill dams because of their high strength and low cost [1-7]. Normally, the large-scale conventional triaxial compression (LCTC) test (i.e., the confining pressure is constant) is used to study the mechanical properties of RFMs [8-14]. However, during such tests, the loading path is not consistent with that in actual engineering applications. Observation data of dams and the results of finite element calculation analyses have shown that the stress path of RFMs can be approximated as the stress ratio remaining constant during dam construction, and it will become a transitional stress path during reservoir filling (Figure 1) [15]. Moreover, the mechanical properties of RFMs are stress-path dependent [16]. In other words, the stress-strain relationships of the RFMs vary greatly under different loading paths. Therefore, it is necessary to consider the influence of the stress path in the constitutive modelling of RFM.
Many LCTC tests have been conducted for examining the behaviour of RFMs. Marsal $[17,18]$ conducted a series of super LCTC tests (the sample was $1130 \mathrm{~mm}$ in height and $180 \mathrm{~mm}$ in diameter). He found that the peak state friction angle of the RFMs decreases with increasing confining pressures. Indraratna and Salim [19] investigated the stressdilatancy phenomenon of RFMs during the LCTC test. Then, they proposed a relative constitutive equation to improve the stress-dilatancy relationship by incorporating particle breakage. Araei et al. [20] conducted the LCTC tests of RFMs under cyclic loading conditions and studied the effect of loading frequency on the sample. Xiao et al. [21, 22] performed several LCTC tests of RFMs with different initial void ratios and investigated the effects of density and pressure on the strength and deformation of RFMs. However, the confining pressure of the LCTC test was constant, and under the stress path, the changing confining pressure had a significant impact on the mechanical behaviour (such as strength, stress-strain relationship, and dilatancy) of the RFMs. Although many 


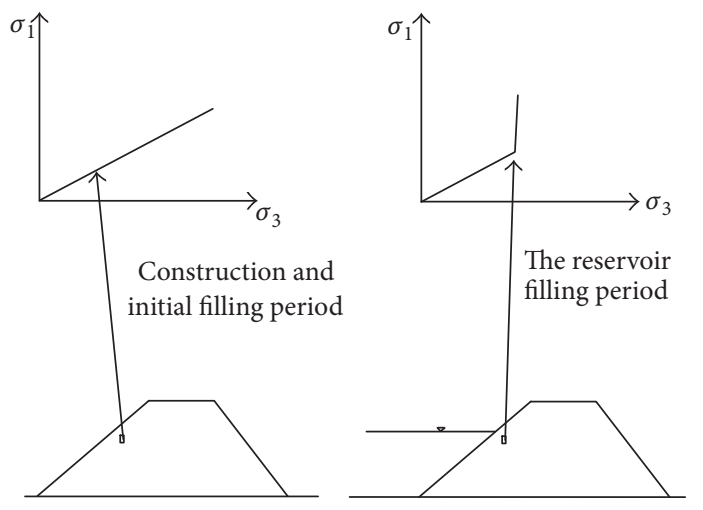

Figure 1: Stress path of RFMs in the dam.

stress path tests of granular material had been conducted, these tests primarily focused on sand. Few stress path tests have been reported for RFMs. Liu et al. [23] conducted several large-scale triaxial tests of Yixing RFM under different stress paths way. Subsequently, they determined that the stress path has little influence on the shear strength of the RFMs. Yang et al. [24] performed large-scale triaxial tests of RFM under three types of loading conditions, in which the confining pressure, mean principal stress, and the principal stress ratio were constant. They observed that the plastic work could well reflect the breakage of coarse-grained material under different loading conditions. However, the loading conditions of these tests were not consistent with those in an actual dam. Stress path tests, which can reflect the real stress state of the RFMs in a dam, have not been conducted.

Based on large-scale triaxial tests, many constitutive models have been proposed for RFMs. Schofield and Wroth [25] proposed the critical state theory, which represents the beginning of modern soil mechanics. Many scholars have employed the concept of critical state line (CSL) in models for RFMs. However, the critical state theory does not apply to RFMs under low stress conditions (where the confining pressure is less than $500 \mathrm{kPa}$ ), because the critical state phenomenon of the sample is often not observed. Duncan and Chang [26] proposed Duncan-Chang's E-u and E-B models. The parameters of these two models can easily be selected from the test and have explicit physical meanings. Therefore, these models are widely used for simulating the deformation behaviour of RFMs. Finite element analyses using these two models have shown that the calculation of the settlement displacement is acceptable, but the calculated horizontal displacement considerably differs from the observation data, which indicates that the model based on the LCTC tests is still incomplete. Several models based on stress path tests have been proposed for RFMs by fitting the test curve [27], but these models are too simple and the theoretical studies are not sufficiently thorough. Although many constitutive models have been proposed for RFMs, the model based on the stress path test has not been fully investigated. With the development of the high rockfill dam, a thorough study of the stress path model for RFMs is urgently needed.
In recent years, increasingly more researchers have begun to model granular materials from the particle length scale. The discrete element method is a commonly used approach for studying the effect of particle properties on macroparticle assemblies. Liu et al. [28] investigated breakage of the rockfill particles in a dam model using Particle Flow Code (PFC) software. Discrete element modelling of sand under onedimensional compression and creep conditions was studied by McDowell and De Bono [29] using the PFC software; however, the calculation speed of PFC is slow; it is difficult to analyse the actual engineering. The M-A model not only appropriately considers the microstructure of soils but also is easier to be applied in engineering practice. Based on this model, Chang and Hicher [30] simulated the conventional triaxial test of Hostun sand under drained and undrained conditions. The simulation results showed that the model could well describe the stress-strain behaviour of the sand during the test. Chang et al. [31, 32] introduced a new slip mechanism of the contact plane in the $\mathrm{M}$ A model; consequently, the model could well reflect the dilatancy phenomenon of Hostun sand under compression and extension loading conditions. Yin et al. [33] proposed a new formulation that accounts for the stress reversal on a contact plane and the density state-dependent dilatancy. Subsequently, the M-A model was extended to be capable of simulating sand under cyclic loading. Previous studies of the M-A model primarily focused on the mechanical properties of sand. The models for RFMs have not been investigated as intensively as the models for sand. Li proposed the M-A model for RFMs based on LCTC tests, and the simulation results indicated that the model could well describe the deformation properties of RFMs during the test [34]. However, modelling of RFMs under the stress path has not been conducted.

In this paper, the M-A model is extended to make it capable of simulating the triaxial tests of NRFM under the stress path. The model is improved by considering the parameter variations under unloading-reloading conditions and the stress transition path. The local dilatancy relations at interparticle planes due to applied load are also discussed. The features of the M-A model are described in comparison with Duncan-Chang's models. Finally, the overall applicability of the proposed model is evaluated through comparisons of the prediction and test results.

\section{Two Types of Large Triaxial Tests}

RFMs were taken from the site of Nuozadu rockfill dam, which is the highest rockfill dam in China (ranked the third highest in the world). Specific details of the study site are presented in Table 1. These materials are used as the main rockfill of the core-dam body. Table 2 presents the basic properties of the NRFM, including particle shape, specific density, initial void ratio, and compressive strength. As shown in Figure 2, the particle size distribution of the prototype NRFM is reduced using the parallel gradation technique [35], with a maximum particle size of $60 \mathrm{~mm}$. The uniformity coefficient $\mathrm{Cu}$ and the curvature coefficient $\mathrm{Cc}$ of the NRFM are 8.8 and 1.47 , respectively. 
TABLE 1: Project and site for NRFM.

\begin{tabular}{lc}
\hline Project detail & Depiction \\
Project name & Nuozhadu Hydropower Station \\
Dam type & Rockfill dam with clay core \\
Site & Puer City, Yunnan Province, China \\
Type of NRFM & Blasted rock \\
\hline
\end{tabular}

TABle 2: Physical and mechanical properties of rockfill.

\begin{tabular}{lc}
\hline Material & Nuozhadu rockfill \\
Particle shape & Angular \\
Specific density $\rho_{s}\left(\mathrm{~g} / \mathrm{cm}^{3}\right)$ & 2.63 \\
Initial void ratio $e_{0}$ & 0.32 \\
Compressive strength $(\mathrm{Mpa})$ & 118.6 \\
\hline
\end{tabular}

The test equipment is a large triaxial apparatus. The specimen is $302 \mathrm{~mm}$ in diameter and $655 \mathrm{~mm}$ in height. The maximum confining pressure of the device is $2500 \mathrm{kPa}$, the maximum axial force is $1000 \mathrm{kN}$ (compression), and the maximum axial displacement is $200 \mathrm{~mm}$. The specimen was compacted and then saturated with $\mathrm{CO}_{2}$ and air-free water ( $B$-value was above 0.96 after saturation). The specimen was consolidated at an initial confining pressure of $40 \mathrm{kPa}$. Then, it was loaded at the set value of stress ratio (as shown in Figures 3 and 4) under the drained condition, which was consistent with the practical working conditions of NRFM in the dam. Because the pore water pressure was zero, all the stresses in this paper refer to the effective stresses.

Ten samples were prepared for the tests. According to the loading method, the samples could be divided into two types. For the first type of test (Figure 3), the sample was loaded under the paths of a constant stress ratio (CSR). When the confining pressure reached $1600 \mathrm{kPa}$, a cycle of unloading and reloading was applied under the same CSR. After the cyclic loading, the loading was continued until the confining pressure $\sigma_{3}$ reached $2500 \mathrm{kPa}$. Because there were six different stress ratios in the tests, six samples were required.

For the second type of test (Figure 4 ), the stress ratio was maintained constant $(q / p=d q / d p=1.00)$ during the initial stage. Then, at each confining pressure, $\sigma_{3 t}=300,800,1400$, and $2000 \mathrm{kPa}$, the confining pressure was held constant and the axial load was increased $(d q / d p=3.00)$ until the samples reached failure. Four samples were required according to the four transitional points.

\section{Constitutive Model}

In the proposed constitutive model, the rockfill sample is considered to be a collection of grains. The deformation of the sample is generated by moving contacted grains in all orientations (Figure 5). Thus, the stress-strain relationship of the NRFM can be obtained from the average of the mobilized deformation of all contact planes between the rockfill grains. The forces and movements at all contact planes are used to obtain the macroscopic stress and strain tensors (Figure 7). The macroscopic stiffness tensor is obtained by integrating the stiffness properties at interparticle contacts. A statically

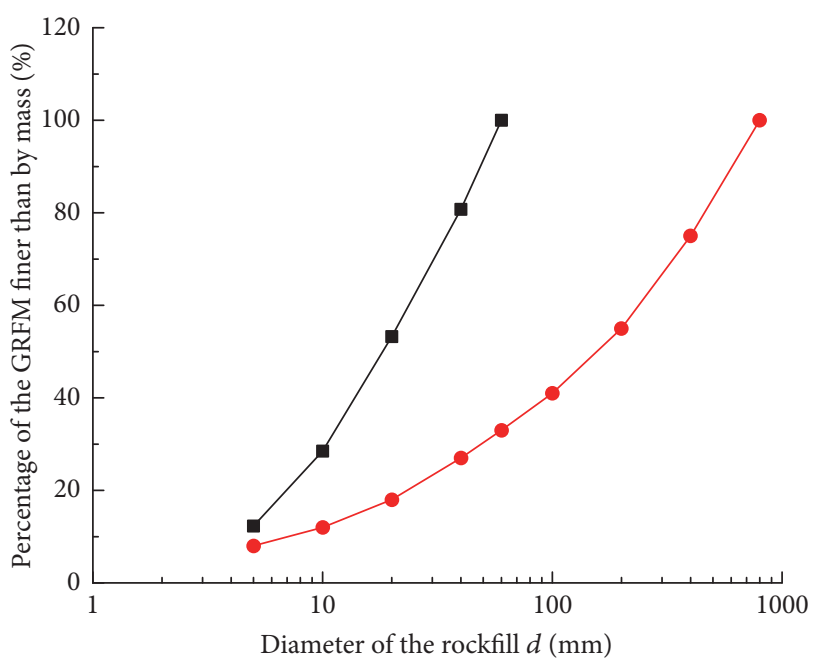

$$
\begin{aligned}
& \text { PSD: particle size distribution } \\
& \rightarrow-\text { Test PSD } \\
& \longrightarrow \text { Prototype PSD }
\end{aligned}
$$

FIgURE 2: Particle size distribution of NRFM.

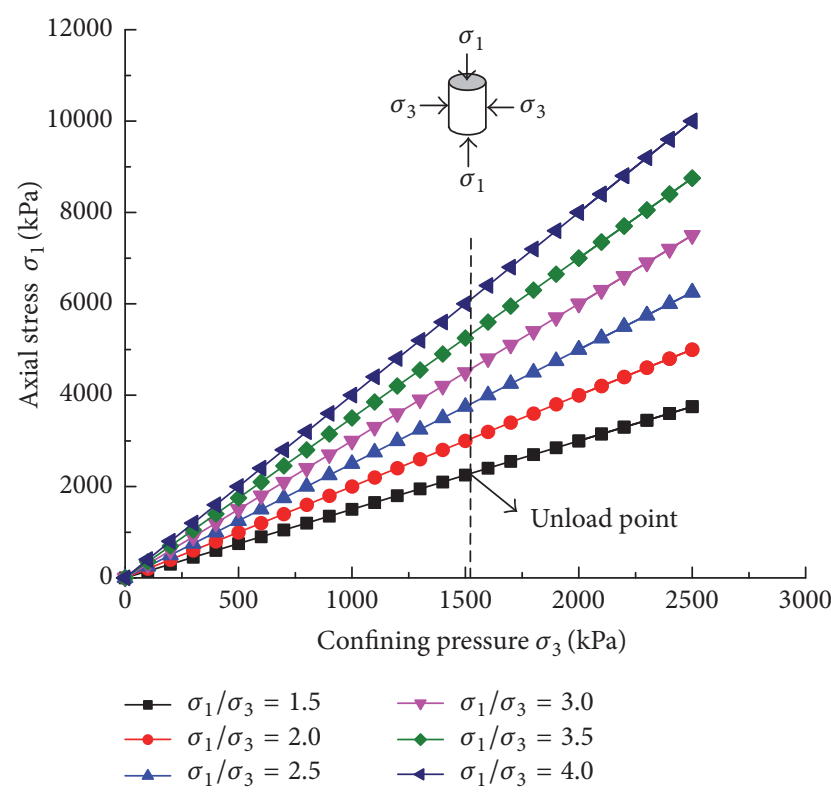

FIgURE 3: Stress paths of constant stress ratio.

constrained microstructure is assumed for the micro-macro links, which means that the forces on each contact plane are assumed to be equal to the resolved components of the macroscopic stress tensor [30].

3.1. Local Coordinates and Definitions. As shown in Figure 5, an auxiliary local coordinate is established on each contact plane. The orientation of a contact plane between two grains is defined by the vector perpendicular to the plane. For the $a$ contact plane, the local forces $F_{I}^{\alpha}$ and the local movements $\delta_{I}^{\alpha}$ can be denoted as follows: $F_{I}^{\alpha}=\left\{F_{n}^{\alpha}, F_{s}^{\alpha}, F_{t}^{\alpha}\right\}$ and $\delta_{I}^{\alpha}=$ $\left\{\delta_{n}^{\alpha}, \delta_{s}^{\alpha}, \delta_{t}^{\alpha}\right\}$, where the subscripts $n, s$, and $t$ represent three orthogonal unit vectors that form the local coordinate system. 


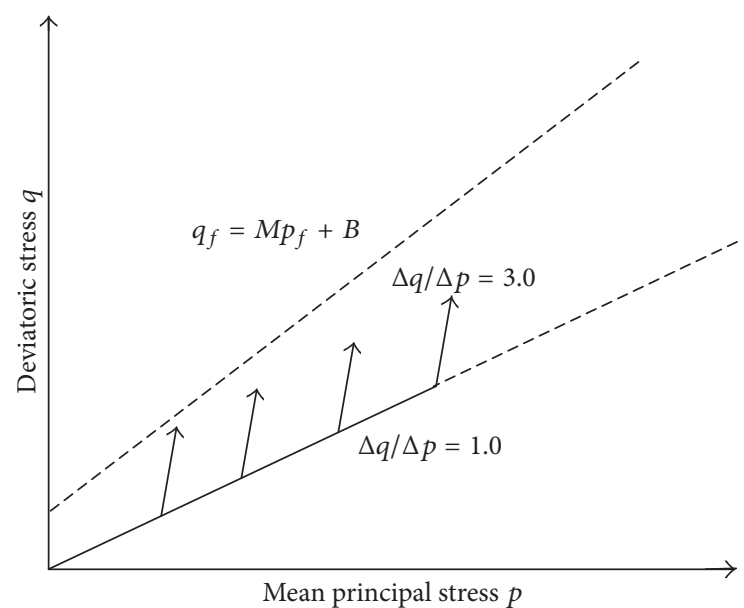

FIGURE 4: Stress paths of constant stress ratio with a transition.

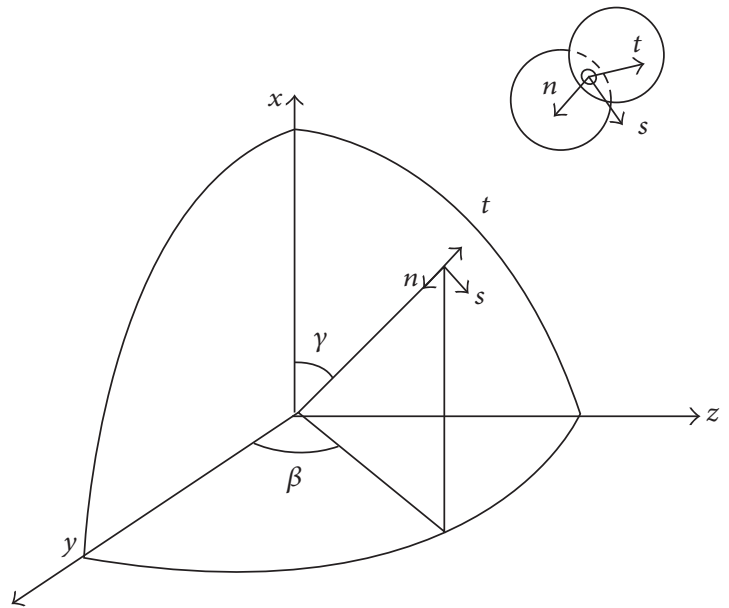

FiguRE 5: Local coordinate at interparticle contact.

The vector $n$ is inward normal to the contact plane. Vectors $s$ and $t$ are on the contact plane.

\subsection{Force-Displacement Relations of the Contacted Grains}

3.2.1. Elastic Part. Suppose that the relationship of the local forces $F_{I}^{\alpha}$ and the local movements $\delta_{I}^{\alpha}$ is nonlinear elasticity. The contact stiffness of the plane includes normal stiffness $K_{n}^{\alpha}$ and shear stiffness $K_{s}^{\alpha}$ and $K_{t}^{\alpha}$. The elastic stiffness is given by

$$
\begin{aligned}
& d F_{n}^{\alpha}=K_{n}^{\alpha} d \Delta_{n}^{\alpha e}, \\
& d F_{s}^{\alpha}=K_{s}^{\alpha} d \Delta_{s}^{\alpha e}, \\
& d F_{t}^{\alpha}=K_{t}^{\alpha} d \Delta_{t}^{\alpha e} .
\end{aligned}
$$

The tensor forms of (1) are as follows:

$$
d F_{I}^{\alpha}=K_{I J}^{\alpha} d \Delta_{J}^{\alpha e}, \quad(I, J=n, s, t) .
$$

It is clear that $K_{I J}^{\alpha}$ is a diagonal matrix, which is as follows:

$$
K_{I J}^{\alpha}=\left[\begin{array}{ccc}
K_{n}^{\alpha} & 0 & 0 \\
0 & K_{s}^{\alpha} & 0 \\
0 & 0 & K_{t}^{\alpha}
\end{array}\right] .
$$

In the global coordinate system, (2) can be expressed as

$$
d f_{i}^{\alpha}=k_{i j}^{\alpha} d \delta_{j}^{\alpha e} .
$$

Then

$$
\begin{aligned}
& k_{i j}^{\alpha}=B_{i I}^{\alpha \prime} K_{I J}^{\alpha} B_{j J}^{\alpha}, \\
& B^{\alpha}=\left[\begin{array}{ccc}
-\cos (\gamma) & -\sin (\gamma) \cos (\beta) & -\sin (\gamma) \sin (\beta) \\
-\sin (\gamma) & \cos (\gamma) \cos (\beta) & \cos (\gamma) \sin (\beta) \\
0 & -\sin (\beta) & \cos (\beta)
\end{array}\right],
\end{aligned}
$$

where, $d f_{i}^{\alpha}$ and $d \delta_{j}^{\alpha e}$ are the increments of the local forces and the local movements in the global coordinate system. $k_{i j}^{\alpha}$ is the stiffness matrix in the global coordinate system. $B^{\alpha}$ is the coordinate transformation matrix. $\beta$ and $\gamma$ are the angles between the vectors and coordinate system (Figure 5).

The value of the elastic stiffness can be estimated from Hertz-Mindlin's formulation [36]

$$
\begin{aligned}
& K_{n}^{\alpha}=K_{n 0}\left(\frac{F_{n}^{\alpha}}{l^{2}}\right)^{n}, \\
& K_{s}^{\alpha}=K_{t}^{\alpha}=K_{r 0}\left(\frac{F_{n}^{\alpha}}{l^{2}}\right)^{n},
\end{aligned}
$$

where $F_{n}^{\alpha}$ is the contact force in the normal direction. $K_{n 0}$, $K_{r 0}$, and $n$ are material constants. $l$ is the branch length between two grains. For two spherical grains, $l$ is the same as the grain size $d$. According to Hertz-Mindlin's theory [36], $n=1 / 3$.

3.2.2. Plastic Part. Stress dilatancy is a well-known phenomenon in RFMs [37-39]. During triaxial tests, the plastic sliding of the particles made the contact plane move, and then shear dilation occurs $[31,32]$. Assuming that that plastic work for a contact plane due to both normal and shear movements is equal to the energy loss due to friction at the contact, the dilatancy effect can be described by

$$
F_{n}^{\alpha} d S_{n}^{\alpha p}+T^{\alpha} d S^{\alpha p}=F_{n}^{\alpha} \tan \varphi d S^{\alpha p} .
$$

Then

$$
\frac{d S_{n}^{\alpha p}}{d S^{\alpha p}}=\tan \varphi-\frac{T^{\alpha}}{F_{n}^{\alpha}},
$$

where $d S_{n}^{\alpha p}$ is the increment of the normal plastic movement. $\varphi$ is the dilatancy angle. $\tan \varphi$ represents the obliquity when the plastic normal movement is zero, which is related to the phase transformation line of the rockfill assembly. The shear 


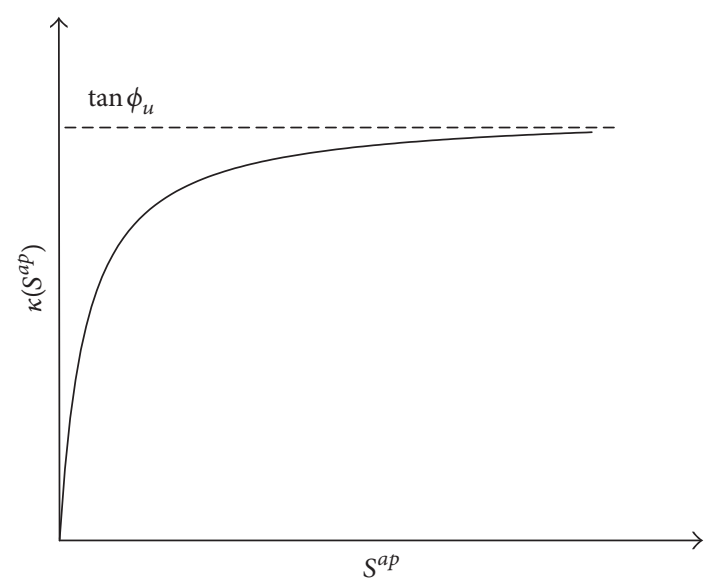

FIGURE 6: The curve of the hardening function in the $\kappa-S^{a p}$ plane.

force $T^{\alpha}$ and the increase of the share plastic movement $d S^{\alpha p}$ can be given by

$$
\begin{aligned}
T^{\alpha} & =\sqrt{\left(F_{s}^{\alpha}\right)^{2}+\left(F_{n}^{\alpha}\right)^{2}}, \\
d S^{\alpha p} & =\sqrt{\left(d S_{s}^{\alpha p}\right)^{2}+\left(d S_{t}^{\alpha p}\right)^{2}} .
\end{aligned}
$$

The yield function is assumed to be of Mohr-Coulomb type

$$
F\left(F_{n}^{\alpha}, \kappa\right)=T^{\alpha}-F_{n}^{\alpha} \kappa\left(S^{\alpha p}\right)=0,
$$

where $\kappa$ is the hardening function, which is defined by a hyperbolic curve (Figure 6) as follows:

$$
\kappa=\frac{K_{p 0} \tan \phi_{u} \cdot S^{\alpha p}}{F_{n}^{\alpha} \tan \phi_{u}+K_{p 0} S^{\alpha p}},
$$

where $\phi_{u}$ is the interparticle friction angle and $K_{p 0}$ is the initial slope of the hyperbolic curve, which can be expressed as follows:

$$
K_{p 0}=k n\left(0.0125+\frac{10}{f_{n}}\right) .
$$

The plastic flow in the direction normal to the contact plane is governed by the stress-dilatancy equation in (8). Thus the flow rule is nonassociated. In the global coordinate system the incremental plastic movements $d \delta_{i}^{\alpha p}$ can be expressed by

$$
\left[\begin{array}{l}
d \delta_{x}^{\alpha p} \\
d \delta_{y}^{\alpha p} \\
d \delta_{z}^{\alpha p}
\end{array}\right]=d S^{\alpha p}\left[\begin{array}{c}
\tan \varphi-\frac{T^{\alpha}}{F_{n}^{\alpha}} \\
\frac{F_{s}^{\alpha}}{T^{\alpha}} \\
\frac{F_{t}^{\alpha}}{T^{\alpha}}
\end{array}\right] B^{\alpha} .
$$

3.3. Macro-Micro Relationship. The stress-strain relationship for the sample can be determined by integrating the behaviour of NRFM interparticle contacts in all orientations.

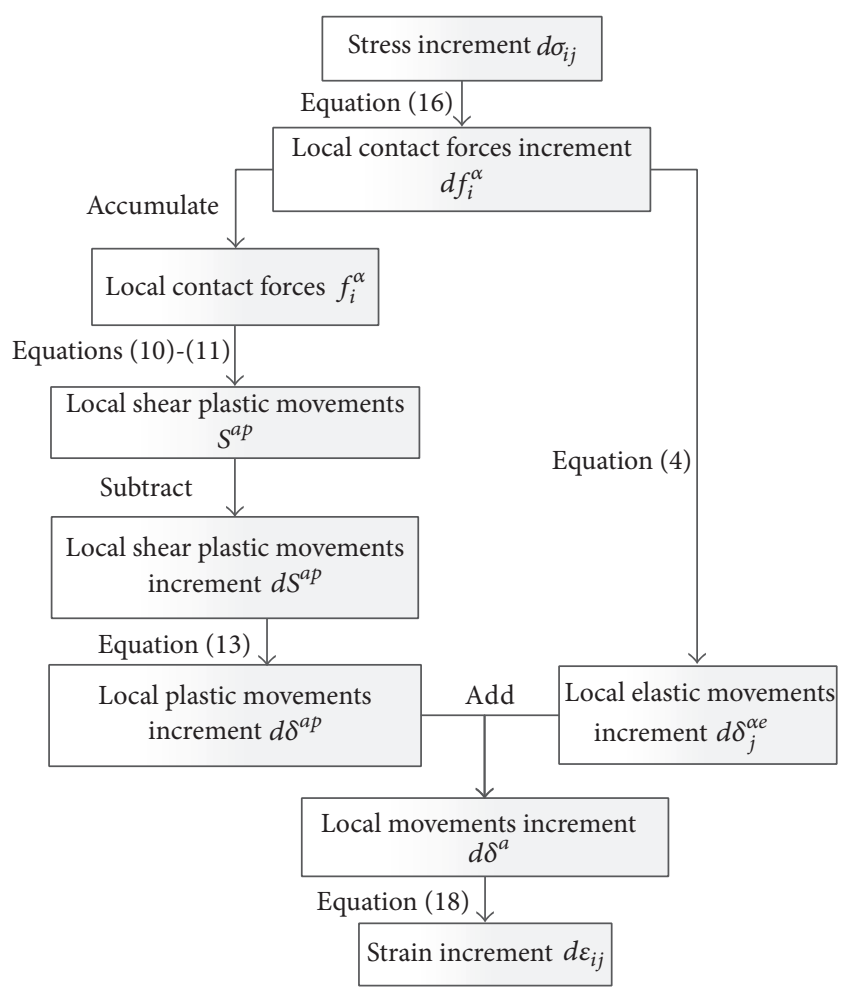

FIGURE 7: Calculation flowchart of the M-A model.

During the integration process, a relationship is required to link the macro and micro variables. Liao et al. [40] proposed that the stress-strain relationship for a granular system could be derived based on the hypothesis that the mean field of displacement is the best fit of actual particle displacements. This relationship has been introduced in the M-A model by Chang et al. and could well describe the stress-strain behaviour of the sand [30-33]. As a kind of granular materials, this hypothesis is also applied to the NRFM. The relation between the macrostrain and interparticle displacement is as follows:

$$
\begin{aligned}
& d \varepsilon_{i j}=A_{i k}^{-1} \sum_{\alpha=1}^{N} d \delta_{j}^{\alpha} l_{k}^{\alpha}, \\
& A_{i k}=\sum_{\alpha=1}^{N} l_{i}^{\alpha} l_{k}^{\alpha},
\end{aligned}
$$

where $d \delta_{j}^{\alpha}$ is the incremental relative displacement between two contacted particles. $l_{k}^{\alpha}$ is the branch vector joining the centres of two contacted particles. $N$ is the total number of contact orientations, according to Oda's research [41], which can be expressed as

$$
\frac{N}{V}=\frac{12}{\pi d^{3}(1+e) e}
$$

Using this hypothesis, the mean force on the contact plane of a given orientation is

$$
d f_{j}^{\alpha}=d \sigma_{i j} A_{i k}^{-1} l_{k}^{\alpha} V
$$


The stress increment can be obtained by the contact forces and branch vectors for all contacts as follows [42, 43]:

$$
d \sigma_{i j}=\frac{1}{V} \sum_{\alpha=0}^{N} d f_{j}^{\alpha} l_{i}^{\alpha}
$$

When the contact number $N$ is sufficiently large in an isotropic packing, the summation of flexibility tensor in (14) can be written in integral form [44], given by

$$
\begin{gathered}
d \varepsilon_{i j}=A_{i k}^{-1} N \int_{0}^{2 \pi} \int_{0}^{\pi} d \delta_{j}^{\alpha}(\gamma, \beta) l_{k}^{\alpha}(\gamma, \beta) \xi(\gamma, \beta) \\
\cdot \sin (\gamma) d \gamma d \beta \\
A_{i k}=N \int_{0}^{2 \pi} \int_{0}^{\pi} l_{i}^{\alpha}(\gamma, \beta) l_{k}^{\alpha}(\gamma, \beta) \xi(\gamma, \beta) \\
\cdot \sin (\gamma) d \gamma d \beta,
\end{gathered}
$$

where $\xi$ is a distribution density function, and in this paper, its value is $1 / 4 \pi$, which means that the sample is isotropic.

\section{Calibrations of Model Parameters}

The model parameters are divided into two parts: the global parameters, which can be chosen from the test, and the interparticle parameters, which cannot be obtained from the test directly. Here, a particle swarm optimization (PSO) algorithm (Figure 8) was used to determine the interparticle parameters.

PSO is a population-based heuristic search technique. Its original concept came from the movements of birds or particles [45]. This algorithm possesses a fast convergence rate and high estimate precision of sensor bias. Therefore, it is widely used in geotechnical engineering. In this algorithm (Figure 8), each potential solution is called a "particle." The solution is searched by a particle swarm flying in the hyperspace. Based on the optimization problem, the objective function of the optimization problem is evaluated for each particles position in the search space. The fitness values of each position are calculated. The best-known positions of each particle are denoted pbest, and the global best position of the entire particle swarm is denoted gbest. For each iteration, the velocity and particle location are expressed by

$$
\begin{aligned}
& V_{i d}^{k+1}=\omega V_{i d}^{k}+c_{1} r_{1}\left(P_{i d}^{k}-X_{i d}^{k}\right)+c_{2} r_{2}\left(P_{g d}^{k}-X_{i d}^{k}\right), \\
& X_{i d}^{k+1}=X_{i d}^{k}+V_{k+1, i d}
\end{aligned}
$$

where $V_{i d}^{k}$ and $X_{i d}^{k}$ are the velocity and the position of the $i$ th particle in the previous iteration, respectively. $r_{1}$ and $r_{2}$ are random numbers ranging from 0 to $1 . c_{1}$ and $c_{2}$ are acceleration coefficients, which are the positive parameters; here, they are equal to $2 . P_{i d}^{k}$ and $P_{g d}^{k}$ are pbest and gbest, respectively.

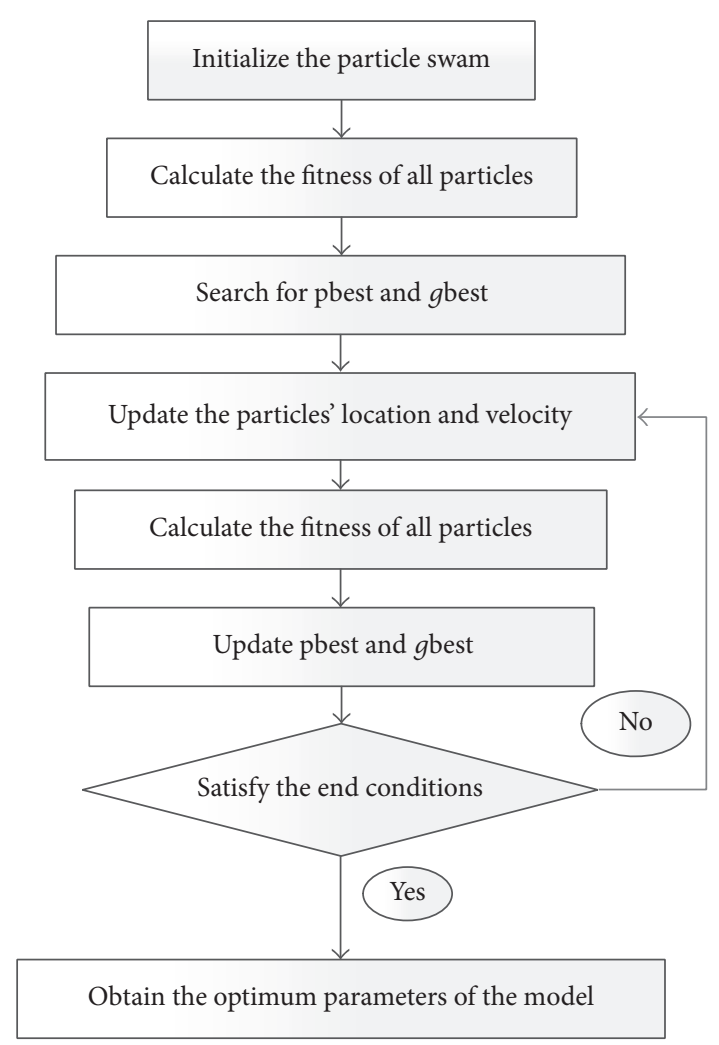

FIGURE 8: Flowchart of the PSO algorithm.

In this paper, the fitness value of the objective function, which determines the POS performance, is represented by the mean squared error, and it is expressed as

$$
E_{r}=\frac{1}{n} \sum_{i=1}^{n}\left(x-x_{t}\right)^{2},
$$

where $x$ is the calculated value, which represents the axial strain and volume strain, respectively; $x_{t}$ is the test data; and $n$ is the total number of test data. As the number of search steps increases, $E_{r}$ will gradually become smaller and satisfy the end conditions.

Table 3 shows the search range of the parameters. According to the initial stress increments and the constitutive model, the optimizer calculates the strain increments. Then, the error $E_{r}$ can be calculated through comparison with test data. The candidate solution is improved throughout the iteration process. When the solution reaches the best fitness, the model parameters are obtained. Considerable efforts were devoted to determining the interparticle parameters of the model under the stress paths of different CSRs. In particular, under unloading-reloading conditions and the stress transition paths, the interparticle parameters might be different; specific instructions are as follows.

Under unloading-reloading conditions, the stress-strain curve is nearly a straight line during the test (Figure 14). Therefore, we assumed that only linear elastic deformation of the particle occurred during this stage (plastic deformation could be neglected). From the analysis of the fitting parameter 
TABLE 3: Parameter-search range of the M-A model.

\begin{tabular}{lcccc}
\hline Material & $K_{n 0}(\mathrm{~N} / \mathrm{m})$ & $\Phi_{u}\left({ }^{\circ}\right)$ & $K_{n}^{a}(\mathrm{~N} / \mathrm{m})$ & $\varphi\left(^{\circ}\right)$ \\
\hline Nuozhadu rockfill & $2.0 \times 10^{8}-3.0 \times 10^{8}$ & $39-40$ & $1.5 \times 10^{7}-2.5 \times 10^{7}$ & $35.6-36.6$ \\
\hline
\end{tabular}

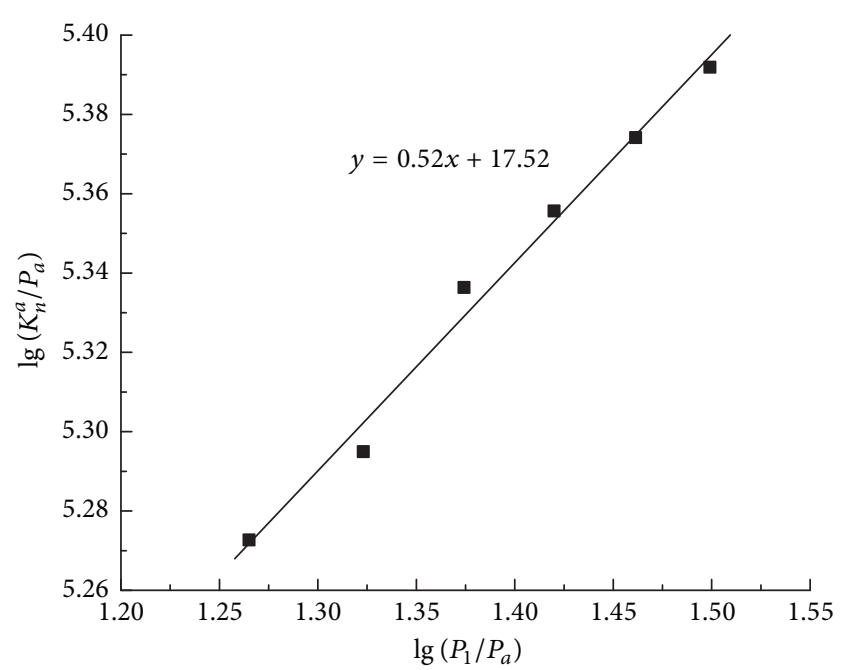

Figure 9: Relationship between normal stiffness and the principal stress at the unloading point.

$K_{n}^{a}$, a significant phenomenon was found: parameter $K_{n}^{a}$ varies regularly with the mean principal stress $P_{1}$ at the unloading point. After plotting $\lg \left(K_{n}^{a} / P_{a}\right)-\lg \left(P_{1} / P_{a}\right)$ in Figure 9, a good linear relationship is observed. Therefore, the value of the normal stiffness for two elastic spheres could be expressed as follows:

$$
K_{n}^{\alpha}=K_{n 1} P_{a}\left(\frac{P_{1}}{P_{a}}\right)^{w},
$$

where $K_{n 1}$ is the intercept of a straight line and $w$ is the slope. The normal stiffness $K_{n}^{a}$ is similar to the loading and unloading modulus of the conventional triaxial test [26], because the two types of tests have similarly shaped deformation curves (see Figure 13(a)).

Under the stress transition path, as the transition confining pressures decrease, the volumetric strain changes from continuous contractancy to final regular dilatancy (as shown in Figure 15). The employed local dilatancy equation (shown as (8)) could well describe the volume changes of sand [31, 32] under compression and extension loading conditions. However, for the NRFM, the large rockfill grains are easily broken as the pressure increases. The abrasion of the rock might reduce the friction coefficient of the contacted particles [46-48]. From the analysis of the fitting parameter $\varphi$, we found that the dilatancy angle $\varphi$ decreased as the transitional confining pressure $\sigma_{3 t}$ increased. As shown in Figure 10, the dilatancy angle $\varphi$ and the transitional confining pressure $\sigma_{3 t}$ exhibit a good linear relationship under the logarithmic coordinates. Here, the dilatancy angle of the contacted particles $\varphi$ can be determined as follows:

$$
\varphi=\varphi_{0}-\Delta \varphi \lg \left(\frac{\sigma_{3 t}}{P_{a}}\right)
$$

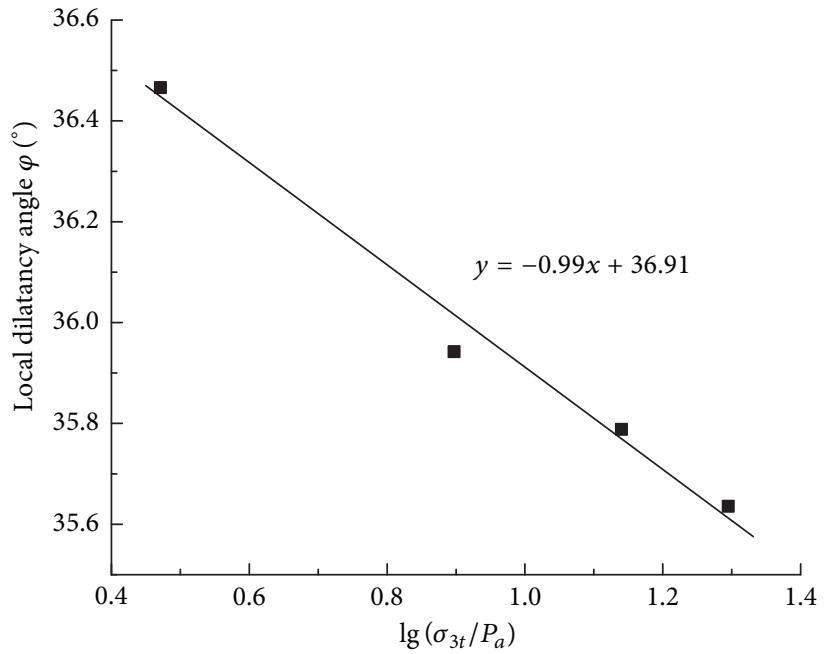

FIGURE 10: Relationship between the dilation angles and the transition confining pressures.

where $\varphi_{0}$ and $\Delta \varphi$ are parameters whose values are equal to the intercept and slope of the line, respectively.

\section{The Evolution of Local Dilatancy at Interparticle Planes}

The stress-dilatancy behaviour of the NRFM calculated using the M-A model is based on the mobilization of contacted particles. Therefore, it is necessary to study the local dilatancy behaviour on individual contact planes between two particles. In the large triaxial test, the applied loads are axisymmetric about the $x$-axis. Therefore, the orientation of the contact plane can be represented by an inclined angle $\gamma$, which can be measured by the branch vector and the $x$-axis, as shown in Figure 11(a). Eight contact planes were selected for the investigation: $\Upsilon=15^{\circ}, 25^{\circ}, 35^{\circ}, 45^{\circ}, 55^{\circ}, 65^{\circ}, 75^{\circ}$, and $85^{\circ}$ (shown in Figure 11(a)).

In order to study the local dilatancy behaviour of the particles, the triaxial test of the type two with the transition confining pressure $\sigma_{3 t}=300 \mathrm{kPa}$ (see Figure 4 ) was chosen to be calculated. According to the employed local dilatancy equation (see (8)), the local dilatancy rate $d S_{n}^{a p} / d S^{a p}$ was defined here. When the value of the local dilatancy rate is negative, the contact plane moves upward and shear-induced dilation occurs; conversely, when the value is positive, the contact plane moves downward and the contraction occurs (Figures 11(g) and 11(h)).

The stress-dilatancy relations for the eight selected contact orientations are plotted in Figures 11(b)-11(i), respectively. During the CSR stage with $q / p=1$, as the load increased, the local dilatancy rate also increased. All the values are positive, which indicate that the contact planes 

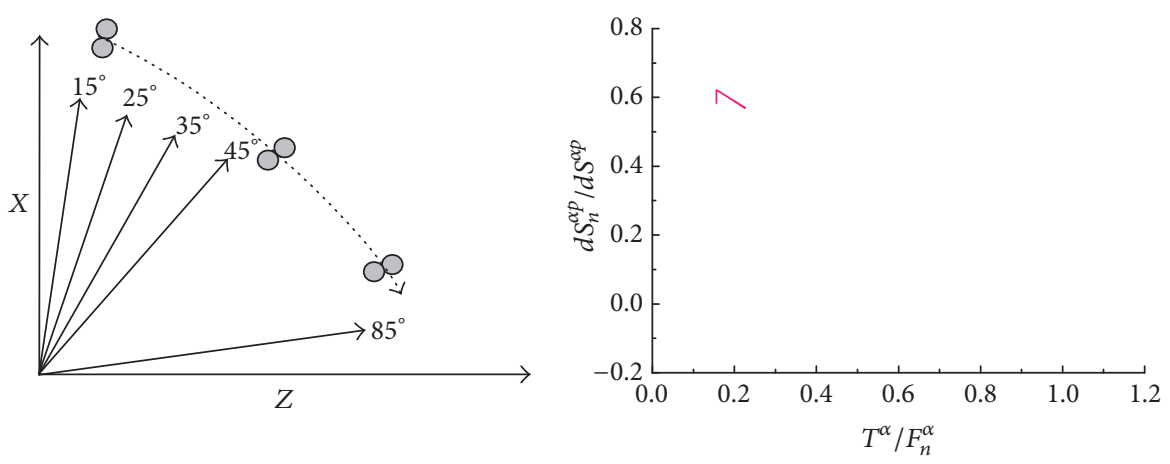

(a)
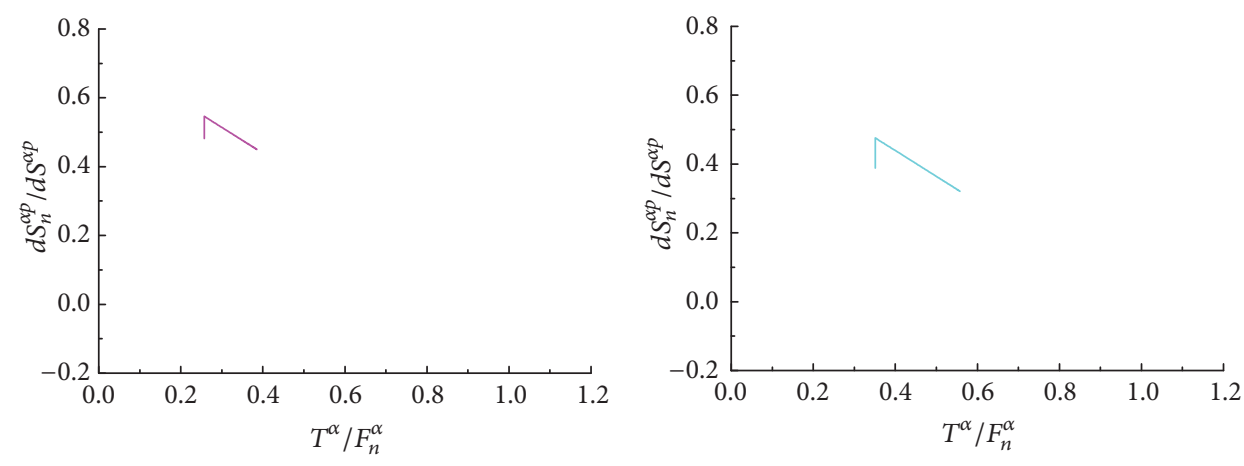

$-25^{\circ}$

$-35^{\circ}$

(c)
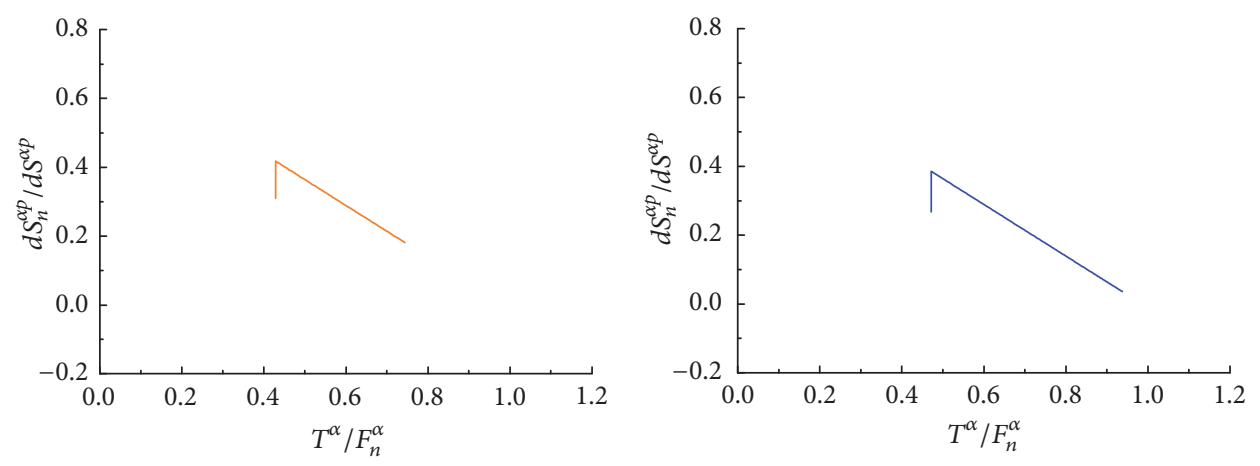

$-45^{\circ}$

(e)

(f)
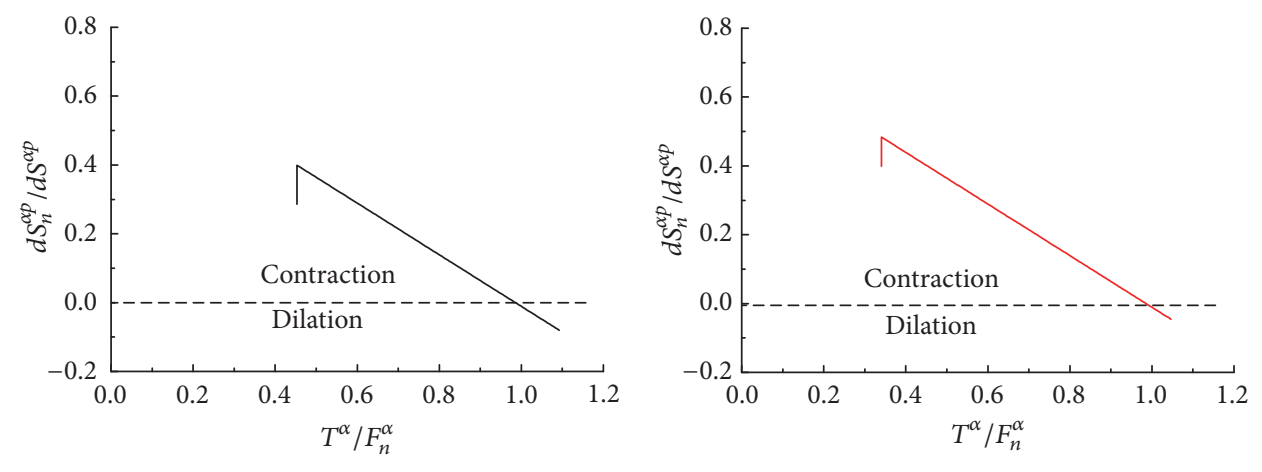

$65^{\circ}$

(g)

(h)

Figure 11: Continued. 


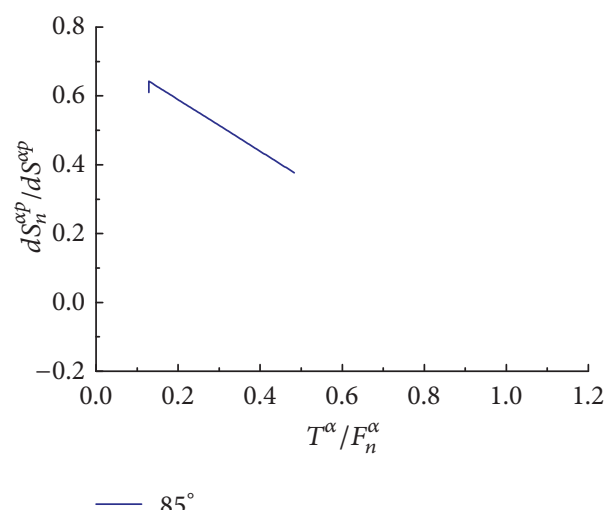

(i)

FIGURE 11: Stress-dilatancy relations for selected contact plane orientations for NRFM.

are contracted. The $65^{\circ}$ contact plane reaches the highest mobilized ratio (close to $\pi / 4+\Phi_{u} / 2=64.6^{\circ}$ ). When stress transition occurred, a clear turning point was observed, as shown in Figures 11(b)-11(i). As the axial force increased, the local dilatancy rate decreased. The contact planes are contracted/dilated at different degree for the given applied stress ratio. The $65^{\circ}$ and $75^{\circ}$ contact planes initially exhibited contraction. Then, they mobilized to higher stress levels and reached the dilation region (Figures $11(\mathrm{~g})$ and $11(\mathrm{~h})$ ). The other planes only exhibited contraction.

Figure 12 shows the relationship of the local dilatancy rate $d S_{n}^{a p} / d S^{a p}$ and the global stress ratio $q / p$. The contact planes are contracted/dilated to different degrees for a given applied stress ratio. Note that the local dilatancy relations, with the planes greater than $55^{\circ}$, are no longer linear when plotted against the global stress ratio. Similar nonlinear relationships were also found during the compression and extension test of Hostun sand simulated by Chang et al. [31, 32].

\section{Comparison and Verification of Constitutive Models}

6.1. Comparison of Predicted Results with Three Models. Duncan-Chang's E-u and E-B models are widely used for calculating the deformation of RFMs. Here, we verify the validity of the M-A models by comparing the predicted results with those of Duncan-Chang's models. The parameters of the models could be obtained from the conventional triaxial tests $\left(\sigma_{3}=\right.$ constant $)$ of the NRFM. Detailed information is available in the literature [49]. The values of the parameters are listed in Table 5. Because there are too many samples to be tested, two samples were chosen to be simulated. One was loaded under a principal stress ratio of $\sigma_{1} / \sigma_{3}=4.0$. The other sample had a transition confining pressure of $\sigma_{3 t}=800 \mathrm{kPa}$ (Figure 13). The comparisons of the predicted results are as follows.

As shown in Figures 13(a) and 13(c), the shapes of the $q \sim \varepsilon_{1}$ curves simulated using the E-u and E-B models are the same. The reason for this result is that, under the same stress conditions, the values of the tangent modulus are equal for the two models. The shapes of the $q \sim \varepsilon_{1}$ curves are similar

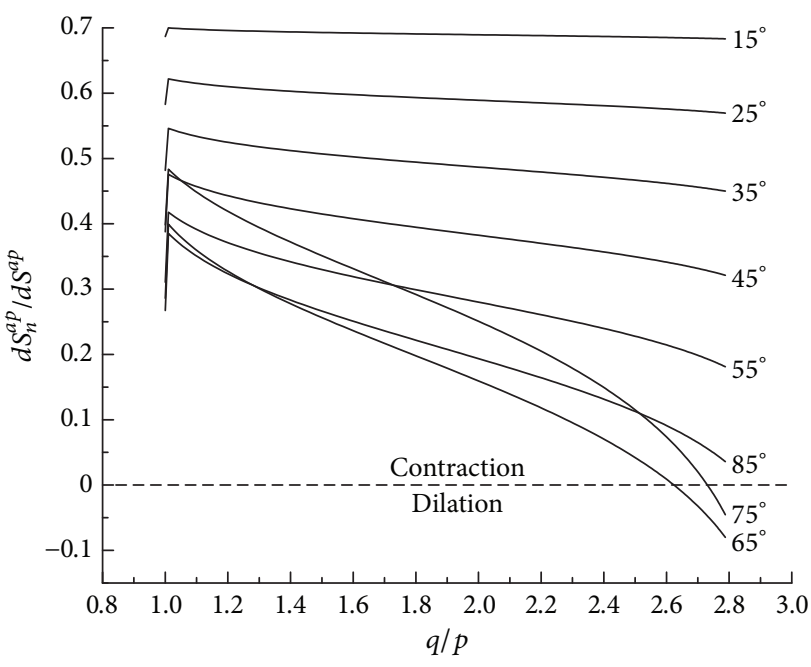

FIGURE 12: Local plastic movement increment versus global stress ratio for selected contact plane orientations.

to that of the test result. However, the calculated values are clearly lower than the test results. The reason might be that the parameters are chosen from the conventional triaxial test; thus, the model cannot reflect the effect of the stress path on the deformation of the samples. The parameters of the M-A model were selected from the stress path test; thus, the simulation results and the experimental results are well fitted.

As shown in Figures 13(b) and 13(d), the $\varepsilon_{v} \sim \varepsilon_{1}$ curves simulated using the E-u and E-B models are both significantly different from the test results. One reason for this result is that the models cannot reflect the effect of the stress path. Another reason is that they cannot describe the dilatancy behaviours of the NRFM due to the limit of elasticity theory. The dilatancy equation (see (8)) of the M-A model could well describe the dilatancy behaviours of the NRFM. Therefore, better simulation results can be obtained.

6.2. M-A Model Predictions. Under CSR loading, the parameters of the extended M-A model were calibrated by using the test data of $\sigma_{1} / \sigma_{3}=1.5,2.5$, and 4.0. Equation (22) 

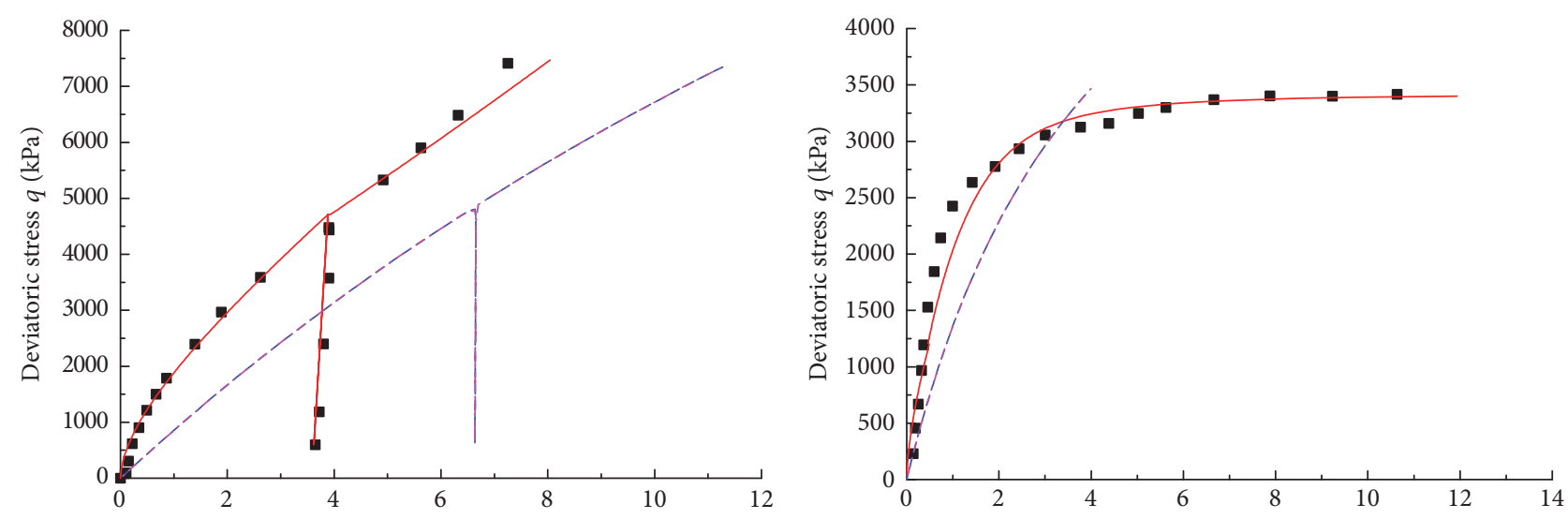

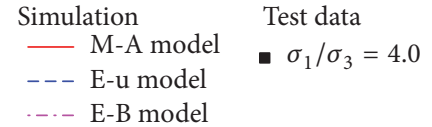

(a)

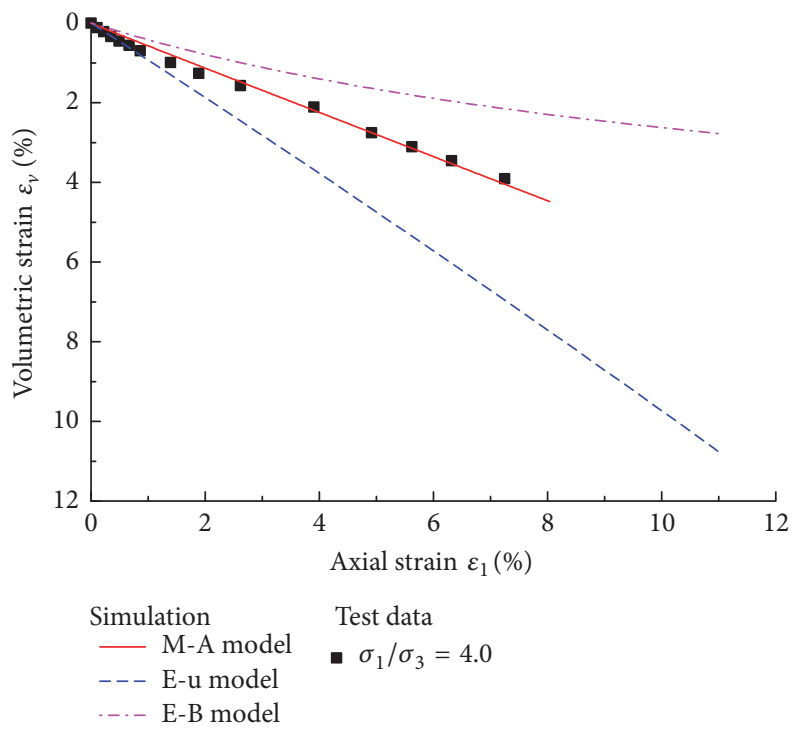

(c)

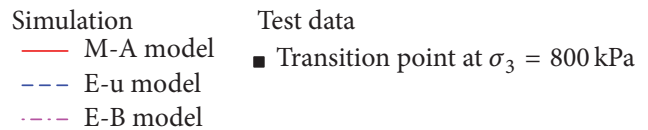

(b)

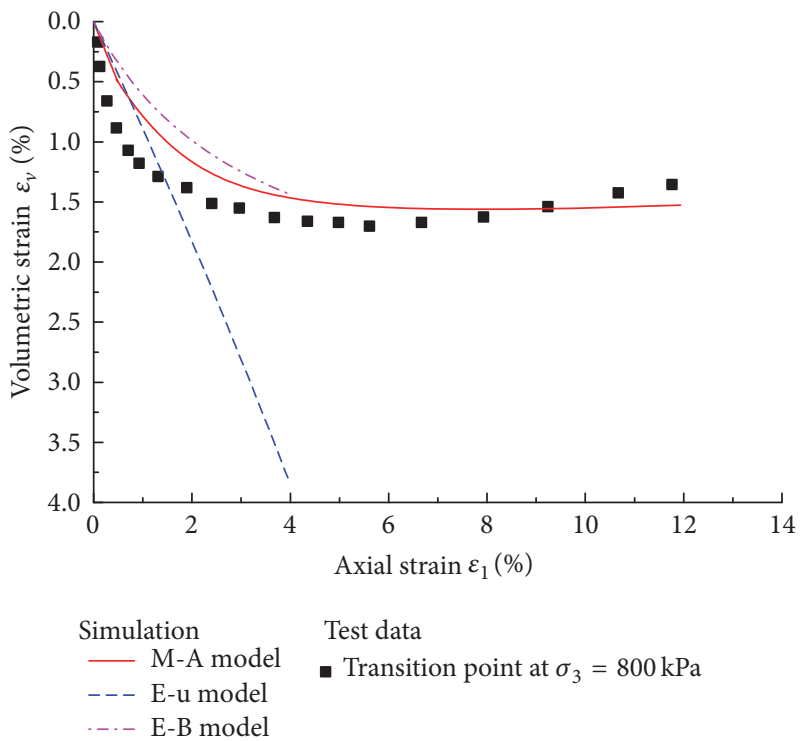

(d)

FIGURE 13: Comparisons between three types of model simulations and test results on NRFM: type one test, (a) and (c): type two test, (b) and (d).

was chosen to determine the normal stiffness $K_{n}^{\alpha}$ under the unloading-reloading conditions. The dilatancy angle $\varphi$ under the stress transition path could be obtained from (23). The diameter of the particle was chosen as the characteristic particle size $D_{50}=18 \mathrm{~mm}$ suggested by Chang and Yin [31]. All the parameters are listed in Tables 2 and 4 . For several tests, without being used for the parameter determination, they were calculated; the calculations could be considered as genuine model predictions. For the unextended M-A model, the details information could be seen in the literature [30].

The comparisons between model predictions and type one test are shown in Figure 14 in terms of the stressstrain-volume relationship on NRFM. The unextended MA model overestimates the deviatoric stress especially under
TABle 4: Parameters of the M-A model.

(a)

\begin{tabular}{lccc}
\hline$K_{n 0}(\mathrm{~N} / \mathrm{m})$ & $n$ & $K_{r 0} / K_{n 0}$ & $\Phi_{u}\left(^{\circ}\right)$ \\
\hline $2.5 \times 10^{8}$ & 0.33 & 0.5 & $39.17^{\circ}$ \\
\hline
\end{tabular}

(b)

\begin{tabular}{lccc}
\hline$K_{n 1}(\mathrm{~N} / \mathrm{m})$ & $w$ & $\varphi_{0}\left({ }^{\circ}\right)$ & $\Delta \varphi\left(^{\circ}\right)$ \\
\hline $3.98 \times 10^{4}$ & 0.52 & $36.91^{\circ}$ & -0.99 \\
\hline
\end{tabular}

unloading-reloading conditions (Figure 14(a)), while the extended model proposed in this paper could well predict the 

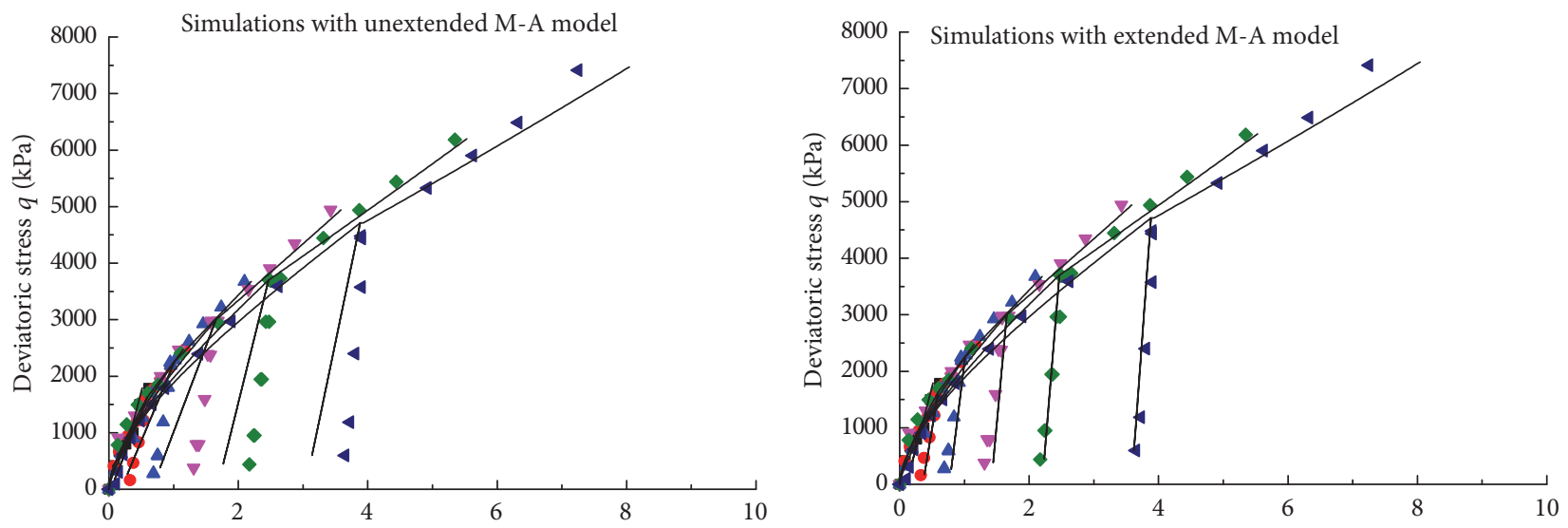

$$
\begin{aligned}
& \text { Test data: } \\
& \begin{array}{l}
\sigma_{1} / \sigma_{3}=1.5 \\
\sigma_{1} / \sigma_{3}=2.0 \\
\begin{array}{l}
\sigma_{1} / \sigma_{3}=2.5 \\
\nabla
\end{array} \quad \sigma_{1} / \sigma_{3}=3.5 \\
\sigma_{1} / \sigma_{3}=3.0
\end{array} \quad \text { Simulation }
\end{aligned}
$$

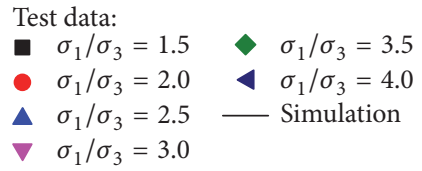
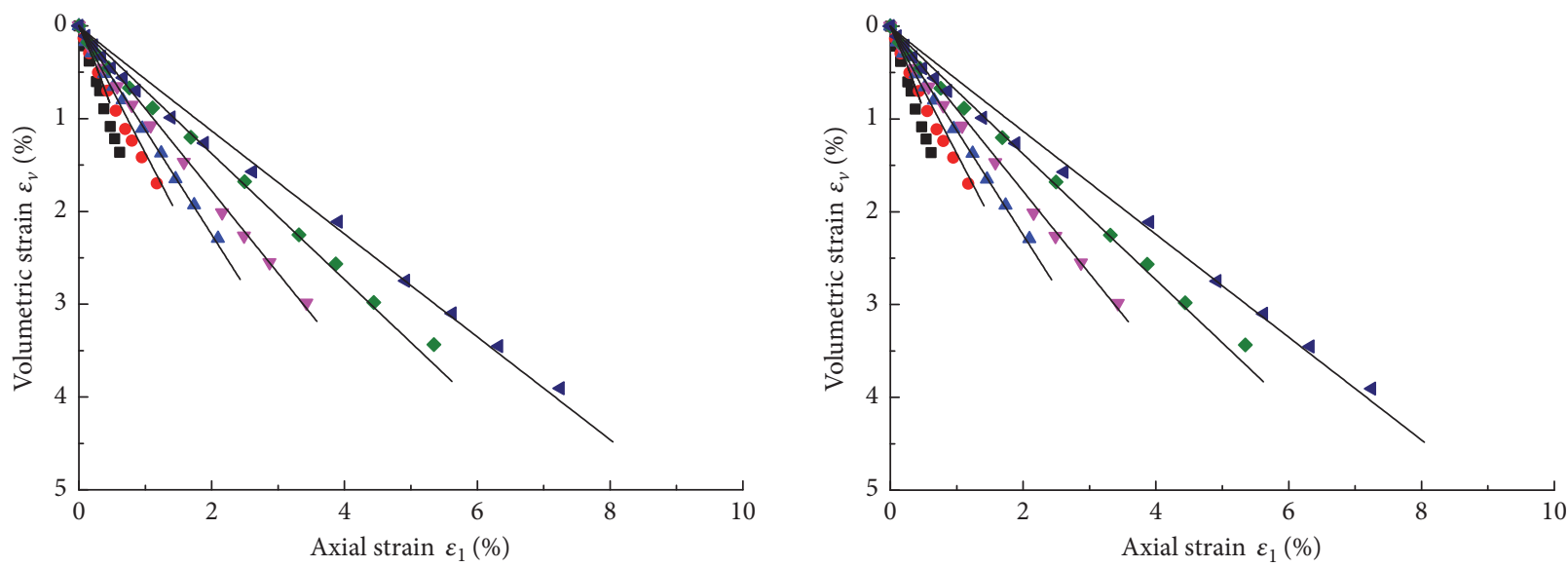

Test data:

- $\sigma_{1} / \sigma_{3}=1.5$

- $\sigma_{1} / \sigma_{3}=2.0$

$\Delta \sigma_{1} / \sigma_{3}=2.5$

$\sigma_{1} / \sigma_{3}=3.5$

$\sigma_{1} / \sigma_{3}=4.0$

$\boldsymbol{\nabla} \sigma_{1} / \sigma_{3}=3.0$

- Simulation

(a)

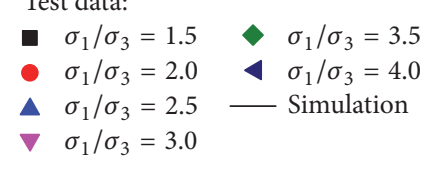

(b)

FIGURE 14: Model simulations of type one test. (a) Comparisons between unextended M-A model simulations and test results on stress-strain relationships of NRFM; (b) comparisons between extended M-A model simulations and test results on stress-strain relationships of NRFM.

TABle 5: Parameters of Duncan-Chang's E-u and E-B models.

\begin{tabular}{lcccccccccc}
\hline Material & $\Phi\left(^{\circ}\right)$ & $\Delta \Phi\left(^{\circ}\right)$ & $R_{f}$ & $K$ & $N$ & $D$ & $G$ & $F$ & $K_{b}$ & $m$ \\
\hline Nuozhadu rockfill & $54.37^{\circ}$ & $10.47^{\circ}$ & 0.72 & 1491 & 0.24 & 7.65 & 0.41 & 0.2 & 683 & 0.10
\end{tabular}

stress-strain-volume behaviour of NRFM under CSR loading (Figure 14(b)). Under CSR loading, all the axial strains are less than $15 \%$. This result indicates that no failure occurred throughout the entire range of tests. Under the unloadingreloading condition, the elastic contact of the particles (proposed in the extended model) could well reflect the linear relationship of the stress-strain curves of the sample. The calculated volumetric-strain curves appear to be linear relationships and match the test data well (Figure 14(b)). Because little changes in the volume occurred during this stage, the calculated volume changes are neglected.

Figure 15 shows the comparisons between the model predictions and type two test. The extended model considering the effect of stress path can well capture the stress-strain 

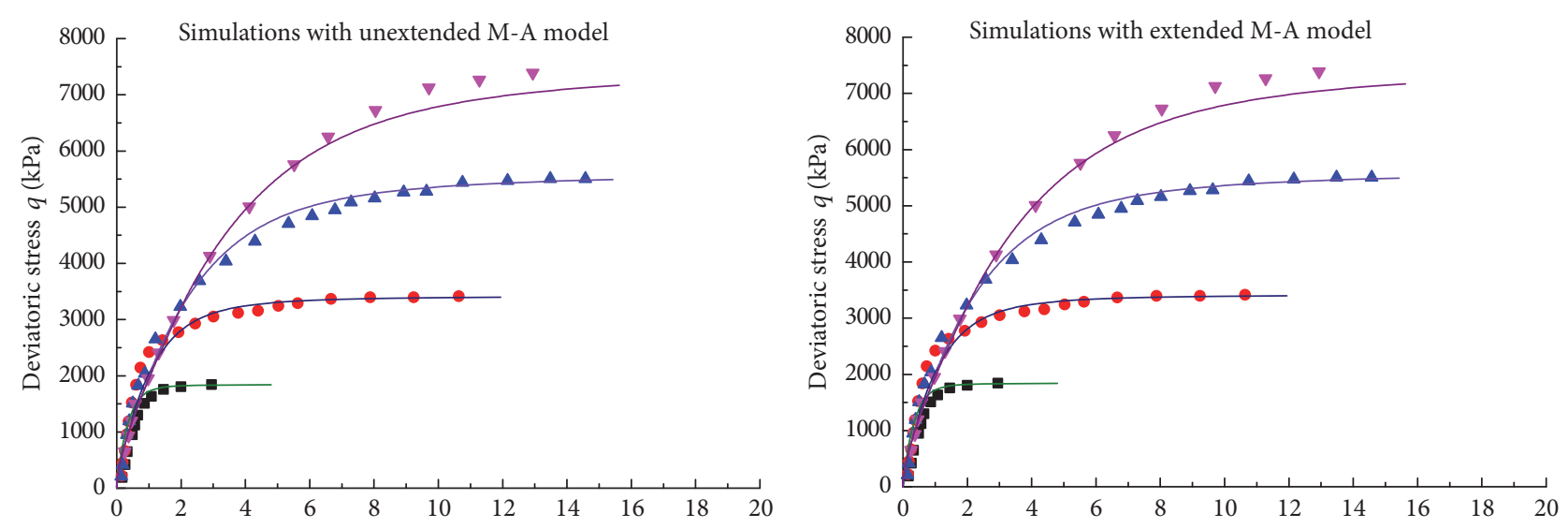

Test data-transitional point at

- $\sigma_{3}=300 \mathrm{kPa} \quad \nabla \sigma_{3}=2000 \mathrm{kPa}$

- $\sigma_{3}=800 \mathrm{kPa}$ Simulation

\ $\sigma_{3}=1400 \mathrm{kPa}$

Test data-transitional point at

- $\sigma_{3}=300 \mathrm{kPa} \quad \nabla \sigma_{3}=2000 \mathrm{kPa}$

- $\sigma_{3}=800 \mathrm{kPa}$ Simulation

\ $\sigma_{3}=1400 \mathrm{kPa}$
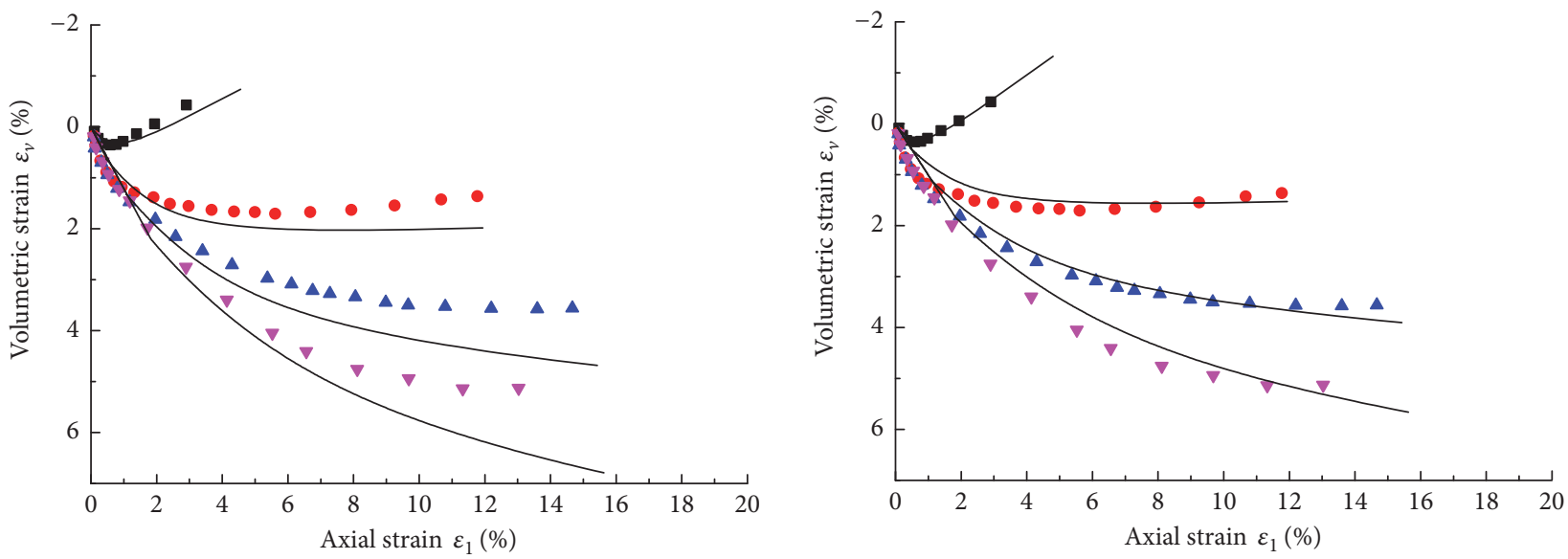

Test data-transitional point at

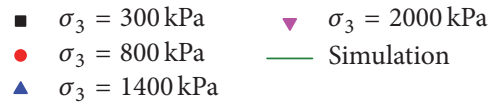

Test data-transitional point at

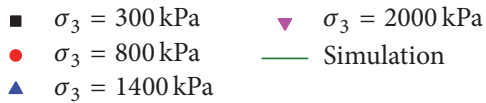

(b)

FIGURE 15: Model simulations of type two test. (a) Comparisons between unextended M-A model simulations and test results on stress-strain relationships of NRFM; (b) comparisons between extended M-A model simulations and test results on stress-strain relationships of NRFM.

relationships of NRFM (Figure 15(b)), while the model without considering the effect of stress path cannot well represent the stress-strain relationship (overestimating the dilation of the NRFM). Under the CSR path, the change in the behaviour of the sample is similar to that of the type one test at $\sigma_{1} / \sigma_{3}=2.5$. However, at the transition confining pressure, the stress path moves towards the failure line and the axial strain rapidly increases. The volume of the sample changes from contraction to dilatancy as the transition confining pressure decreases. Because the load path of the test is similar to the stress variation of the actual RFM in the dam, this model could well describe the constitutive relationship of the NRFM under the paths of a constant stress ratio during dam construction and the transitional stress paths upon reservoir filling.

\section{Conclusions and Discussion}

A micromechanical model considering the effect of stress path was proposed for NRFM. The main conclusions and discussion are summarized below.

The stress path of RFMs during dam construction can be approximated as the CSR load, and it will become a transitional feature upon reservoir filling. Corresponding to these engineering conditions, two types of triaxial drained tests were conducted to simulate the actual stress variations of the NRFM. In the first type of test, no failure occurred, and the NRFM exhibited contraction during the entire loading period. However, in the second type of test, the samples reached the failure point. Dilatancy became increasingly more serious as the transition confining pressure decreased. 
At the particle length scale, the movements of the local contacted planes can well reflect the deformation behaviour of the NRFM sample. The calculation speed of the model is fast, for the mean force and the movements of the contact plane were used to obtain the macro stress and strains. However, the model cannot reflect the deformation characteristics of specific particles.

The M-A model has been extended. For the NRFM under unloading-reloading conditions, the new stiffness of the particles can well predict the linear relationship of the stressstrain curves; for the tests under the stress transition path, the local dilatancy angle can well describe the volume of the sample changing from contractancy to dilatancy. Compared with Duncan-Chang's models, the M-A model could better describe the deformation behaviour of the NRFM under the stress path. Model predictions for the drained triaxial tests have demonstrated that the present micromechanical approach is capable of modelling the deformation behaviours of NRFM under actual stress paths in the dam.

\section{Competing Interests}

The authors declare that there is no conflict of interests regarding the publication of this paper.

\section{Acknowledgments}

This research was supported by the Natural Science Foundation of China (nos. 51179024 and 51379029). The authors gratefully acknowledge the financial support provided by the National Nature Science Foundation of China.

\section{References}

[1] Y. Xiao, H. Liu, Y. Chen, J. Jiang, and W. Zhang, "State-dependent constitutive model for rockfill materials," International Journal of Geomechanics, vol. 15, no. 5, Article ID 04014075, 2014.

[2] G. Hunter and R. Fell, "Rockfill modulus and settlement of concrete face rockfill dams," Journal of Geotechnical \& Geoenvironmental Engineering, vol. 129, no. 10, pp. 909-917, 2003.

[3] M.-S. Won and Y.-S. Kim, "A case study on the post-construction deformation of concrete face rockfill dams," Canadian Geotechnical Journal, vol. 45, no. 6, pp. 845-852, 2008.

[4] Y. Xu and L. M. Zhang, "Breaching parameters for earth and rockfill dams," Journal of Geotechnical \& Geoenvironmental Engineering, vol. 135, no. 12, pp. 1957-1970, 2009.

[5] D. Zou, B. Xu, X. Kong, H. Liu, and Y. Zhou, "Numerical simulation of the seismic response of the Zipingpu concrete face rockfill dam during the Wenchuan earthquake based on a generalized plasticity model," Computers \& Geotechnics, vol. 49, pp. 111-122, 2013.

[6] J. Chen, Y. Sheng, Y. Chou, L. Liu, and B. Zhang, "Cooling effect of crushed rock-based embankment along the chaidaermuli railway," Advances in Materials Science and Engineering, vol. 2015, Article ID 182437, 8 pages, 2015.

[7] S. Huang, X. Ding, Y. Zhang, and W. Cheng, “Triaxial test and mechanical analysis of rock-soil aggregate sampled from natural sliding mass," Advances in Materials Science \& Engineering, vol. 2015, Article ID 238095, 14 pages, 2015.
[8] B. Indraratna, L. S. S. Wijewardena, and A. S. Balasubramaniam, "Large-scale triaxial testing of greywacke rockfill," Geotechnique, vol. 43, no. 1, pp. 37-51, 1993.

[9] B. Indraratna, D. Ionescu, and H. D. Christie, "Shear behavior of railway ballast based on large-scale triaxial tests," Journal of Geotechnical \& Geoenvironmental Engineering, vol. 124, no. 5, pp. 439-449, 1998.

[10] B. Indraratna, J. Lackenby, and D. Christie, "Effect of confining pressure on the degradation of ballast under cyclic loading," Géotechnique, vol. 55, no. 4, pp. 325-328, 2005.

[11] E. Liu, "Breakage and deformation mechanisms of crushable granular materials," Computers \& Geotechnics, vol. 37, no. 5, pp. 723-730, 2010

[12] A. Varadarajan, K. G. Sharma, S. M. Abbas, and A. K. Dhawan, "Constitutive model for rockfill materials and determination of material constants," International Journal of Geomechanics, vol. 6, no. 4, pp. 226-237, 2006.

[13] A. Varadarajan, K. G. Sharma, K. Venkatachalam, and A. K. Gupta, "Testing and modeling two rockfill materials," Journal of Geotechnical \& Geoenvironmental Engineering, vol. 129, no. 3, pp. 206-218, 2003.

[14] B.-Y. Zhang, Y.-X. Jie, and D.-Z. Kong, "Particle size distribution and relative breakage for a cement ellipsoid aggregate," Computers \& Geotechnics, vol. 53, pp. 31-39, 2013.

[15] B. Xiang, Z.-L. Zhang, and S.-C. Chi, "An improved hypoplastic constitutive model of rockfill considering effect of stress path," Journal of Central South University of Technology, vol. 16, no. 6, pp. 1006-1013, 2009.

[16] M. J. Duncan, S. K. Wong, and P. Mabry, "Strength, stress-strain and bulk modulus parameters for finite element analyses of stresses and movements in soil masses," Journal of Consulting and Clinical Psychology, vol. 49, p. 554, 1980.

[17] R. J. Marsal, "Research on the behavior of granular materials and rockfill samples," Internal Report, Comision Federal de Electricidad, Mexico City, Mexico, 1965.

[18] R. J. Marsal, "Large-scale testing of rockfill materials," Journal of the Soil Mechanics and Foundations Division, vol. 93, no. 2, pp. 27-43, 1967.

[19] B. Indraratna and W. Salim, "Modelling of particle breakage of coarse aggregates incorporating strength and dilatancy," Proceedings of the Institution of Civil Engineers-Geotechnical Engineering, vol. 155, no. 4, pp. 243-252, 2002.

[20] A. A. Araei, H. R. Razeghi, A. Ghalandarzadeh, and S. H. Tabatabaei, "Effects of loading rate and initial stress state on stressstrain behavior of rock fill materials under monotonic and cyclic loading conditions," Scientia Iranica, vol. 19, no. 5, pp. 1220$1235,2012$.

[21] Y. Xiao, H. Liu, Y. Chen, and J. Jiang, "Strength and deformation of rockfill material based on large-scale triaxial compression tests. I: influences of density and pressure," Journal of Geotechnical and Geoenvironmental Engineering, vol. 140, no. 12, Article ID 04014070, 2014.

[22] Y. Xiao, H. Liu, Y. Chen, and J. Jiang, "Strength and deformation of rockfill material based on large-scale triaxial compression tests. II: influence of particle breakage," Journal of Geotechnical and Geoenvironmental Engineering, vol. 140, no. 12, Article ID 04014071, 2014.

[23] M. C. Liu, Y. F. Gao, and H. L. Liu, "Study on shear behaviors of rockfill in large-scale triaxial tests under different stress paths," Chinese Journal of Rock Mechanics and Engineering, vol. 27, no. 1, pp. 176-186, 2008. 
[24] G. Yang, B. Y. Zhang, Y. Z. Yu, and X. Sun, "Experimental study on particle breakage of coarse-grained materials under the stress path," Shuili Xuebao, vol. 41, no. 3, pp. 338-342, 2010.

[25] A. Schofield and P. Wroth, Critical State Soil Mechanics, McGraw-Hill, New York, NY, USA, 1968.

[26] J. M. Duncan and C. Chang, "Nonlinear analysis of stress and strain in soils," Journal of the Soil Mechanics and Foundations Division, vol. 96, no. 5, pp. 1629-1653, 1970.

[27] B. Xiang, Z. Z. Liang, and S. C. Chi, "Three-modulus incremental nonlinear model of rockfill under paths of constant stress ratio," Chinese Journal of Geotechnical Engineering, vol. 30, no. 9, pp. 1322-1326, 2008.

[28] F. H. Liu, J. Liu, and X. J. Kong, "PFC numerical simulation of particle breakage of the Clay Core Rock-fill Dam," in Advances in Discontinuous Numerical Methods and Applications in Geomechanics and Geoengineering, pp. 307-313, CRC Press, Boca Raton, Fla, USA, 2012.

[29] G. R. McDowell and J. P. De Bono, "A new creep law for crushable aggregates," Géotechnique Letters, vol. 3, no. 3, pp. 103-107, 2013.

[30] C. S. Chang and P.-Y. Hicher, "An elasto-plastic model for granular materials with microstructural consideration," International Journal of Solids and Structures, vol. 42, no. 14, pp. 42584277, 2005.

[31] C. S. Chang and Z.-Y. Yin, "Modeling stress-dilatancy for sand under compression and extension loading conditions," Journal of Engineering Mechanics, vol. 136, no. 6, pp. 777-786, 2010.

[32] Z.-Y. Yin and C. S. Chang, "Stress-dilatancy behavior for sand under loading and unloading conditions," International Journal for Numerical and Analytical Methods in Geomechanics, vol. 37, no. 8, pp. 855-870, 2013.

[33] Z.-Y. Yin, C. S. Chang, and P.-Y. Hicher, "Micromechanical modelling for effect of inherent anisotropy on cyclic behaviour of sand," International Journal of Solids \& Structures, vol. 47, no. 14-15, pp. 1933-1951, 2010.

[34] S. C. Chi, S. J. Li, and F. Wang, "Research on constitutive model of rockfill material with microstructure consideration," Journal of North China University of Water Resources and Hydropower, vol. 36, p. 1, 2015.

[35] J. Lowe, "Shear strength of coarse embankment dam materials," in Proceedings of the 8th International Congress on Large Dams, pp. 745-761, Edinburgh, UK, 1964.

[36] R. D. Mindlin, "Micro-structure in linear elasticity," Archive for Rational Mechanics and Analysis, vol. 16, no. 1, pp. 51-78, 1964.

[37] Y. Xiao, H. Liu, H. Liu, Y. Chen, and W. Zhang, "Strength and dilatancy behaviors of dense modeled rockfill material in general stress space," International Journal of Geomechanics, vol. 16, no. 5, Article ID 4016015, 2016.

[38] Y. Xiao, H. Liu, Y. Sun, H. Liu, and Y. Chen, "Stress-dilatancy behaviors of coarse granular soils in three-dimensional stress space," Engineering Geology, vol. 195, pp. 104-110, 2015.

[39] J. Liu, D. Zou, X. Kong, and H. Liu, "Stress-dilatancy of Zipingpu gravel in triaxial compression tests," Science China Technological Sciences, vol. 59, no. 2, pp. 214-224, 2016.

[40] C.-L. Liao, T.-P. Chang, D.-H. Young, and C. S. Chang, "Stressstrain relationship for granular materials based on the hypothesis of best fit," International Journal of Solids and Structures, vol. 34, no. 31-32, pp. 4087-4100, 1997.

[41] M. Oda, "Co-ordination number and its relation to shear strength of granular material," Soils and Foundations, vol. 17, no. 2, pp. 29-42, 1977.
[42] J. Christoffersen and M. M. Mehrabadi, "A micro-mechanical description of granular material behavior," Journal of Applied Mechanics, vol. 48, no. 2, pp. 339-344, 1981.

[43] N. P. Kruyt and L. Rothenburg, "Statistics of the elastic behaviour of granular materials," International Journal of Solids and Structures, vol. 38, no. 28-29, pp. 4879-4899, 2001.

[44] C. S. Chang, S. J. Chao, and Y. Chang, "Estimates of elastic moduli for granular material with anisotropic random packing structure," International Journal of Solids and Structures, vol. 32, no. 14, pp. 1989-2008, 1995.

[45] J. Kennedy and R. C. Eberhart, "Particle swarm optimization," in Proceedings of the IEEE International Conference on Neural Networks, vol. 4, pp. 1942-1948, Perth, Australia, December 1995.

[46] C. J. Nieto Gamboa, Mechanical Behavior of Rockfill MaterialsApplication to Concrete Face Rockfill Dams, Ecole Centrale de Paris, Châtenay-Malabry, France, 2011.

[47] Y. Wang, W. Dan, Y. Xu, and Y. Xi, "Fractal and morphological characteristics of single marble particle crushing in uniaxial compression tests," Advances in Materials Science and Engineering, vol. 2015, Article ID 537692, 10 pages, 2015.

[48] M. Saadati, P. Forquin, K. Weddfelt, and P. L. Larsson, "On the tensile strength of granite at high strain-rates considering the influence from pre-existing cracks," Advances in Materials Science \& Engineering, vol. 2016, Article ID 6279571, 9 pages, 2016.

[49] B. Xiang, Study on Constitutive Relations of Rockfill under Complex Stress Path, Dalian University of Technology, Dalian, China, 2009. 


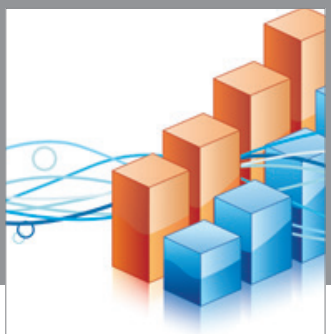

Advances in

Operations Research

vatem alat4

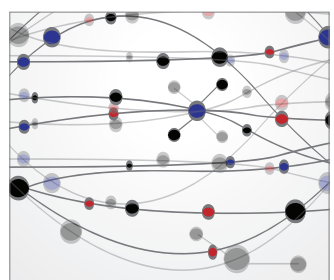

\section{The Scientific} World Journal
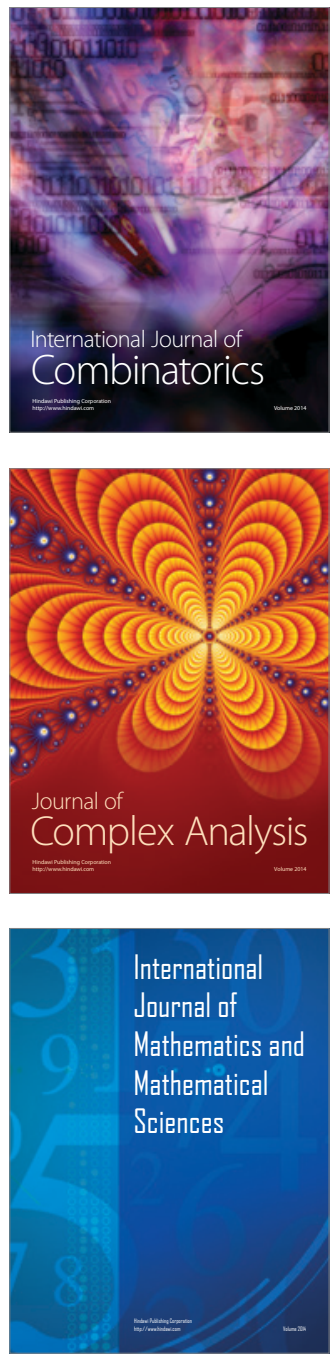
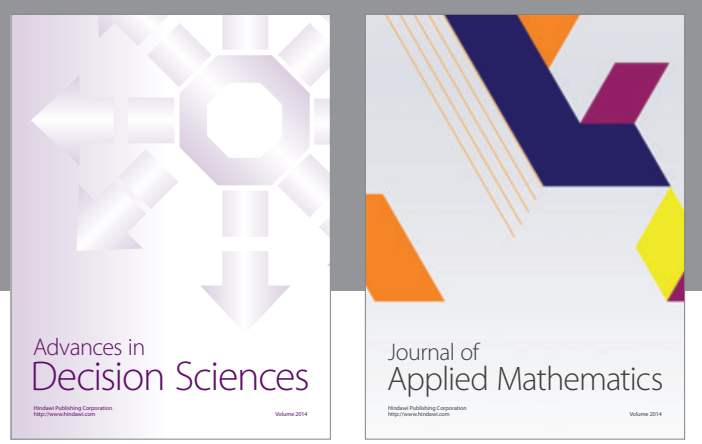

Algebra

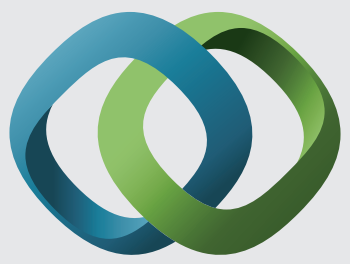

\section{Hindawi}

Submit your manuscripts at

http://www.hindawi.com
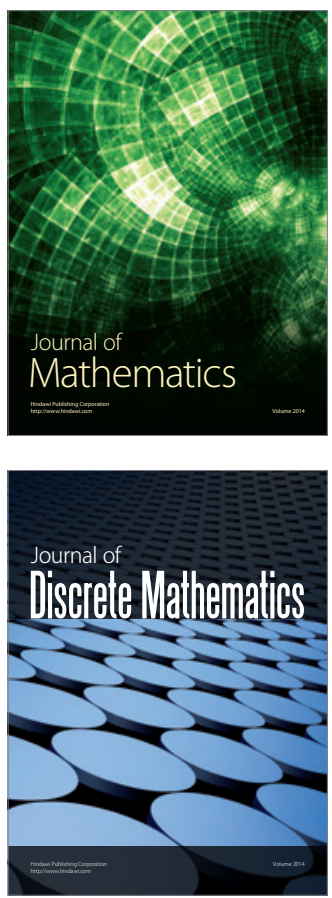

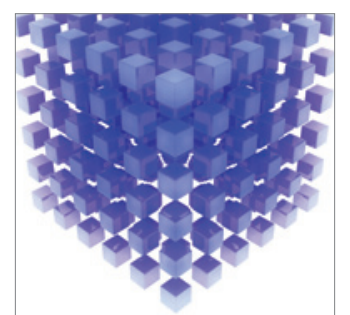

Mathematical Problems in Engineering
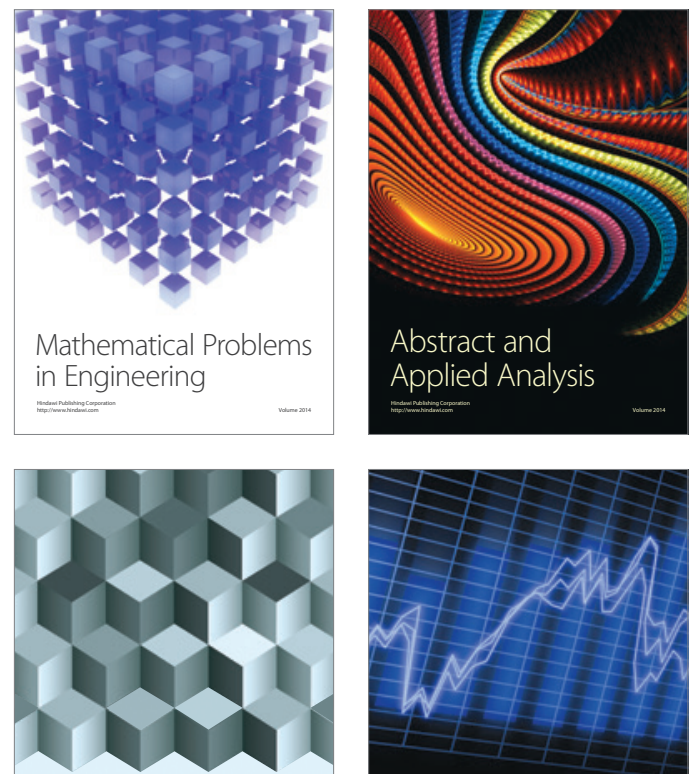

Journal of

Function Spaces

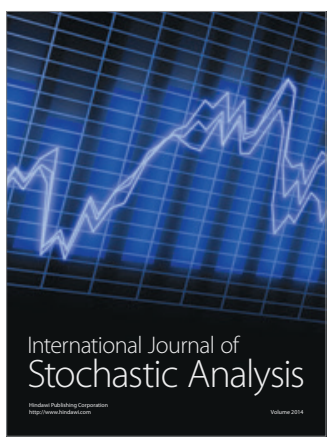

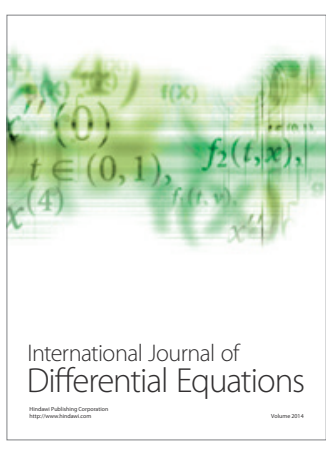
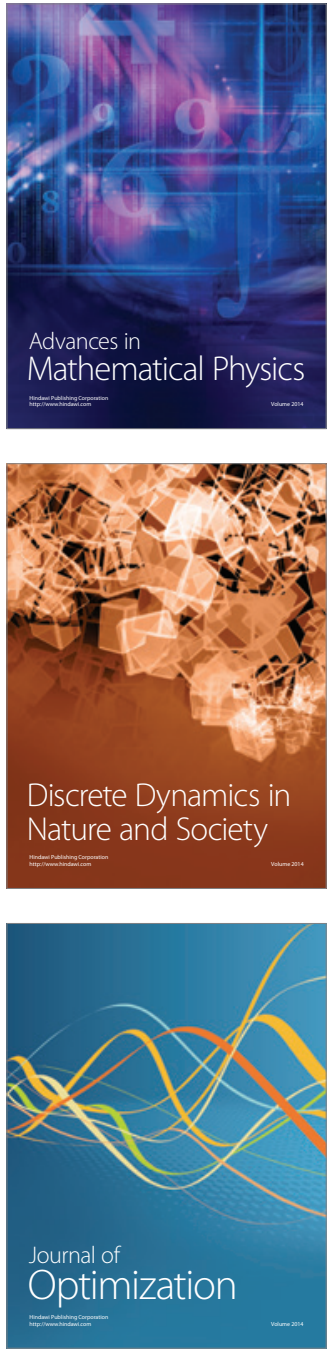